\title{
Development of Treatment Technology for Dye Containing Industrial Wastewater
}

\author{
M. S. I. Mozumder* and M. A. Islam \\ Department of Chemical Engineering and Polymer Science, Shahjalal University of Science and \\ Technology, Sylhet-3114, Bangladesh
}

Received 29 January 2010, accepted in final revised form 10 July 2010

\begin{abstract}
The removal of Congo red was carried out by heating with changing $\mathrm{pH}$, using coagulant and by adsorption. Acidic $\mathrm{pH}$ was favorable for the removal of Congo red by heating. It is possible to remove a major portion of Congo red just by decreasing the $\mathrm{pH}(<4)$. Removal studies suggest that coagulation might be the major mode of dye removal. It is becoming a promising alternative to replace or supplement the present dye removal processes from wastewater. In these studies, removal of Congo red from aqueous solution by coagulation and flocculation was investigated. Treatment with alum and lime was found to be the most effective. Activated charcoal is also an effective adsorbent for the removal of Congo red. From the isotherm (Langmuir and Freundlich) and kinetics study we find that the Congo red-activated charcoal system has high affinity and capacity.
\end{abstract}

Keywords: Congo red; Coagulation; pH; Temperature; Adsorption; Activated charcoal. (C) 2010 JSR Publications. ISSN: 2070-0237 (Print); 2070-0245 (Online). All rights reserved. DOI: $10.3329 /$ jsr.v2i3.4302 J. Sci. Res. 2 (3), 567-576 (2010)

\section{Introduction}

In Bangladesh, many textile industries discharge their effluents directly to nearby river. This effluent contains dyes and pigments that are very harmful to the aquatic life. Some of these wastes are highly toxic due to the presence of a large number of metal complex dyes like Congo red. The industrial dye compounds, aromatic amines are often suspected to be carcinogens [1]. In addition, color interferes with the transmission of sunlight into the stream and therefore reduces photosynthetic action. Many researchers have studied different techniques for removal of colored dye from wastewater, e.g., micellarenhanced ultrafiltration [2], several oxidation processes [3,4], ozonations [5], nanofiltration [6],

\footnotetext{
*Corresponding author: salatulislam@yahoo.co.in
} 
adsorption onto agricultural solid waste [7], different bentonites [8], various types of activated carbon [9], and surfactant impregnated montmorillonite [10], coagulation [11], biological treatments [12] etc. Ultrafiltration (UF) and nanofltration (NF) can be used for complete removal of all classes of dye, but care is needed to avoid membrane fouling which decreases the flux. Due to low biodegradability of dyes, the conventional biological wastewater treatment process is not very efficient in treating dye containing wastewater [13]. Physical and chemical treatment processes are generally used in this situation.

Congo red, the most available and industrially applicable dye that draws the attention in this study, is called direct or substantive dye. Congo red (1-Naphthalenesulfonic acid, 3,3-(4,4-biphenylenebis(azo)) bis (4-amino-) disodium salt) is a benzidine-based dye which structure is described in Fig. 1.

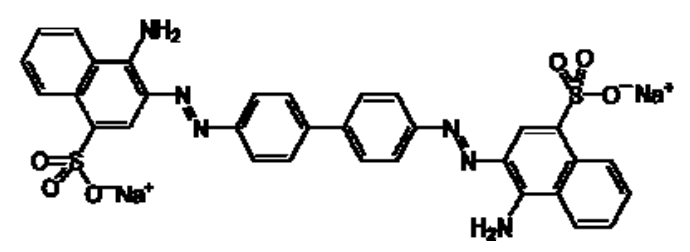

Fig. 1. Chemical structure of Congo red.

The Congo red is known to metabolize to benzidine, a known human carcinogen and exposure to the dye has caused an allergic reaction (and possibly, anaphylactic shock). Red dyes having better fastness properties on cotton are now available, but most of them are more expensive than Congo red. Moreover it has the natural ability to attach on any surface because of its excellent adhesion properties (attributed to its capability of hydrogen-bond formation). For this reason, the Congo red, in spite of its belongings to aromatic amine groups (which are suspected to be carcinogens), is extensively used in textile industries. As a consequence, a large amount of wastewater containing Congo red is being produced in these industries and the removal of the dye in a cost effective way becomes an important task for our industries and environmental protection.

This experimental study has been done to make an overview on cost effective removal technique to remove Congo red from industrial wastewater. We conducted batch experiments and found effective process such as coagulation, removal based on $\mathrm{pH}$, lime wash and adsorption. The effect of coagulant dosage and lime dosage on the dye-removal efficiency was also studied. $\mathrm{pH}$ and temperature also has a large influence for the removal of Congo red. The Congo red makes agglomerate at low $\mathrm{pH}$ and then settle down. So the settling of Congo red agglomerates in acidic conditions also an effective method for the removal of this azo-dye and this method is not much studied yet. The combined effect of $\mathrm{pH}$ and heating reduce the residence time and increase the efficiency of the removal process. Lime and coagulant together, reduce the process time and increase the efficiency and the settling velocity in Congo red removal process. Adsorption is also a well- 
established method for the removal of both organic and inorganic compounds and also metals. Here we use activated charcoal to effectively remove the Congo red. Isotherm and kinetics parameters are investigated for this adsorption system.

\section{Materials and Methods}

\subsection{Chemicals}

The stock solution of Congo red (200 mg/l) was prepared by dissolving Congo red in distilled water. $0.1 \mathrm{M}$ Hydrochloric acid $(\mathrm{HCl})$ and $0.1 \mathrm{M}$ Sodium Hydroxide $(\mathrm{NaOH})$ were used for controlling the $\mathrm{pH}$. Lime and alum were used for the evaluation of coagulation effect on Congo red removal. All the chemicals used were of analytical reagent grade and were obtained from MERCK, Germany.

\subsection{Analyses}

Batch mode coagulation and other processes were conducted to determine the removal efficiency of the system. In $\mathrm{pH}$ and temperature dependent removal technique, we took $200 \mathrm{ml} 100 \mathrm{ppm}$ solution and make the desired $\mathrm{pH}$. The experiment was run in temperature range $25-100^{\circ} \mathrm{C}$. The Separation is carried out by centrifugation and the residual Congo red was analyzed spectrophotometrically (UV-1601, Shimadzu, Japan). For the coagulation process, the tests were carried out with different amounts of lime and alum with $200 \mathrm{ml}$ of Congo red solution of desired concentrations and shaking the mixture continuously at 400 osc/min for 6 hours at room temperature.

The activated charcoal (supplied by MARCK, Germany) has the strong adsorption capacity to remove the Congo red. To determine the isotherm and kinetics parameters, the experiments were conducted by shaking $300 \mathrm{mg}$ of adsorbent with $200 \mathrm{ml}$ of Congo red solution of desired concentrations at 400 osc/min for 6 hours at room temperature and neutral $\mathrm{pH}$. The adsorbate was separated from the adsorbent by centrifugation.

\section{Results and Discussion}

\subsection{Removal of Congo red by heating and changing $\mathrm{pH}$}

Congo red is blue in color at low $\mathrm{pH}$ but Red at high $\mathrm{pH}$. It is a dipolar molecule $\left(\mathrm{H}_{3} \mathrm{~N}^{+}\right.$$\mathrm{R}^{-\mathrm{X}_{3}^{-}}$) at low $\mathrm{pH}$. The molecular form of Congo red in solution could change significantly at $\mathrm{pH}$ 4. At $\mathrm{pH} \mathrm{2,} \mathrm{the} \mathrm{dye} \mathrm{solution} \mathrm{changed} \mathrm{its} \mathrm{color} \mathrm{from} \mathrm{Red} \mathrm{to} \mathrm{dark} \mathrm{blue;} \mathrm{the}$ precipitated dye can be efficiently removed by filtration [14]. The hydrophobic interactions between the aromatic rings of the dye molecules, lead to a pi-pi stacking phenomenon. Although these aggregates are present under various sizes and shapes, the "ribbon-like micelles" of a few molecules seem to be the predominant form. This aggregation phenomenon is more prevalent in high Congo red concentration, at low $\mathrm{pH}$. The higher the temperature, faster the reaction and is more effective in the coagulation. The sedimentation constant as well as the settling velocity increase with the temperature. 
But the precipitations vary with $\mathrm{pH}$ with respect to time. When temperature was raised to the system in acidic medium it increased collisions between the dye particles which could easily settle down.

The percentage removal of Congo red with temperature at various $\mathrm{pH}$ is shown in Fig. 2. The removal of dye at lower $\mathrm{pH}$ was found to be greater compared to that at a higher $\mathrm{pH}$.

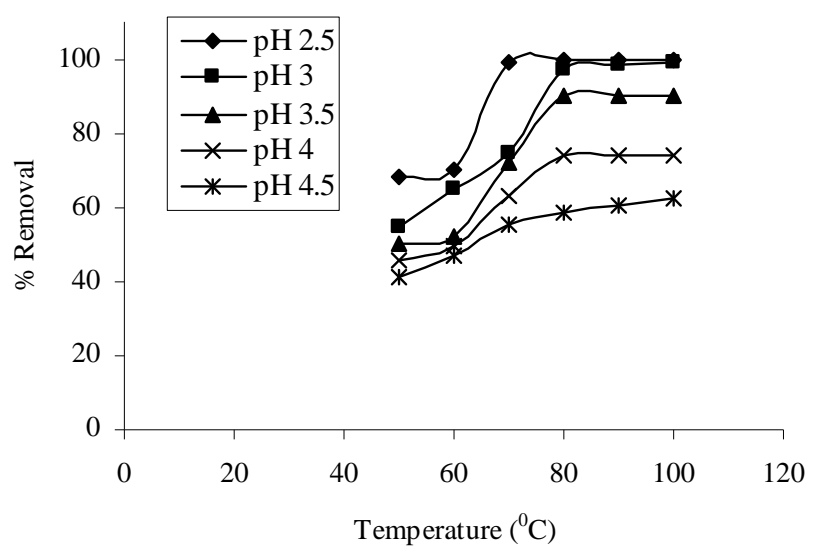

Fig. 2. Effect of temperature on removal of Congo red at different $\mathrm{pH}$.

For $\mathrm{pH} 2.5$, the removal was $99 \%$ before the temperature reaches to $70{ }^{0} \mathrm{C}$. The precipitation occurred rapidly between the temperatures of 60 to $70{ }^{0} \mathrm{C}$. The removal was $81.02 \%$ at $100{ }^{0} \mathrm{C}$ temperature of the solution having $\mathrm{pH} 3.0$ but as the heating was continued at this temperature for another 30 minutes, the removal was reached to $98.66 \%$. At pH 3.5 the removal was $90.16 \%$ and there was no change with continuous heating at the maximum temperature $100{ }^{\circ} \mathrm{C}$. At $\mathrm{pH} 4.0$ the removal was reached to $74.02 \%$ at 80 ${ }^{0} \mathrm{C}$; and no effect on removal if heating was continued at $100{ }^{\circ} \mathrm{C}$ with respect to time. At $\mathrm{pH} 4.5$ removal of Congo red was not so efficient.

In higher $\mathrm{pH}$ (alkaline medium) there was no effect on removal by heating. Therefore the removal of Congo red by heating was suitable only in acidic medium $(\mathrm{pH}<4)$.

\subsection{Removal of Congo red by coagulation}

The coagulation and precipitation technique was used to remove Congo red from waste water. Generally iron or aluminum salts are used as coagulating agent. Here we used lime and alum for this purpose. Congo red was adsorbed onto the lime and the alum was helped the particles to coagulate and settle down. The percentage dye removal with lime dosages for the $100 \mathrm{ppm}$ initial concentration was presented in the Fig. 3. As seen from the figure the removal increased with lime dosage for given initial concentration. 


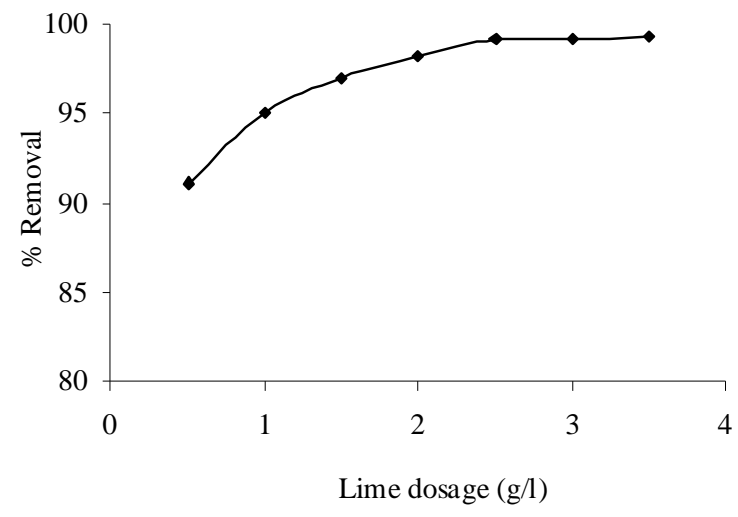

Fig. 3. Effect of lime dosage on removal.

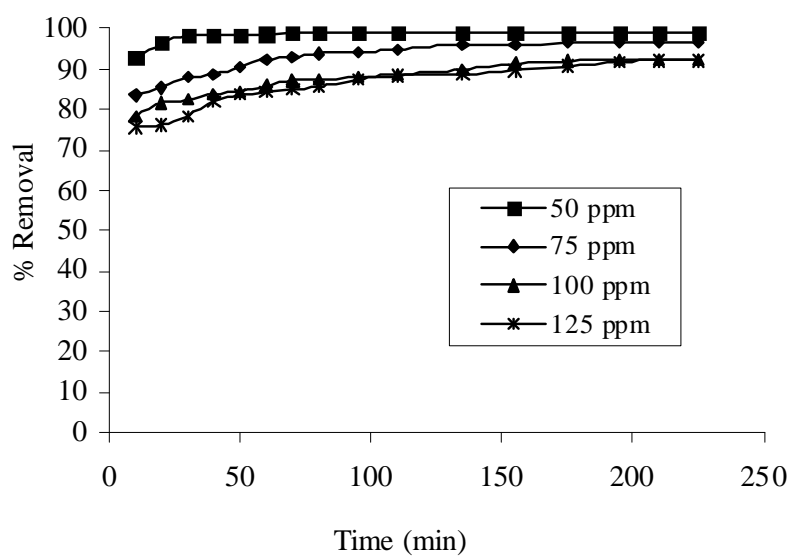

Fig. 4. Removal as a function of time for Congo red-lime system.

The removal of Congo red from wastewater did not only depend on the lime dosage but also the initial concentration and time. Fig. 4 shows the removal with time for different initial concentrations. From this figure, it appeared that the interaction between Congo red and lime reached equilibrium at different times for different initial concentrations. For 50 ppm solution it needed 70 minutes, for 75 ppm it was 135 minutes, for 100 ppm 175 minutes and for 125 ppm 195 minutes. The percentage dye removal at equilibrium decreased from 99 to 92.15 percent as the dye concentration increased from 50 to $125 \mathrm{ppm}$.

A small amount of alum with lime reduced the reaction time and increased the settling velocity. If $0.6 \mathrm{mg} / \mathrm{l}$ alum was used with lime for above-mentioned experiment, it took only 10 minutes to reach equilibrium. 


\subsection{Removal of Congo red by adsorption}

\subsubsection{Adsorption isotherm}

The adsorption characteristics for wide ranges of adsorbate concentration are mostly described by adsorption isotherm (Langmuir or Freundlich), which relates the equilibrium adsorbate concentration in the bulk and the uptake of adsorbate on the adsorbent surface. The Langmuir isotherm (Eq.1) is valid for monolayer adsorption onto a surface containing a finite number of identical sites.

$$
1 / q_{e}=1 /\left(K q_{\infty} C_{e}\right)+1 / q_{\infty}
$$

where $C_{e}$ is the equilibrium concentration (ppm), $q_{e}$ is the amount adsorbed per unit amount adsorbent (mg/g), $K$ and $q_{\infty}$ are Langmuir constants related to the adsorption capacity. If the $1 / q_{e}$ versus $1 / C_{e}$ plot is linear, the adsorption system follows the Langmuir model.

Freundlich isotherm is presented by the following relation:

$$
\ln q_{e}=(1 / n) \ln C_{e}+\ln K_{f}
$$

where $q_{e}$ is the amount of dye adsorbed (mg/gm), $C_{e}$ is the equilibrium dye concentration in solution (ppm), and $K_{f}$ and $n$ are constants incorporating all factors affecting the adsorption process such as adsorption capacity and intensity. Linearity of the $\ln q_{e}$ versus $\ln C_{e}$ plot confirms the follow of Freundlich model of adsorption.

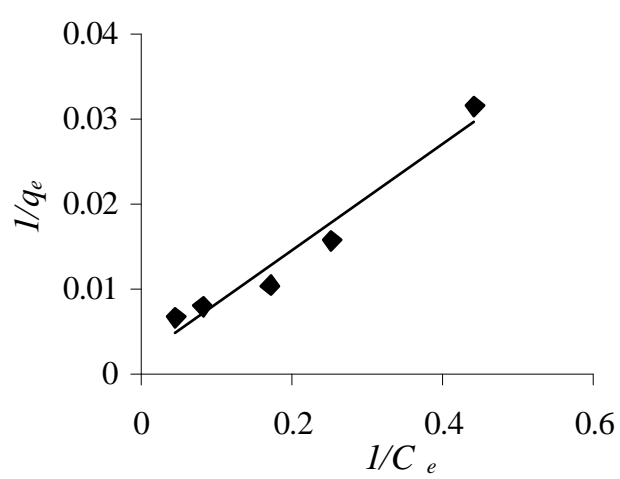

Fig. 5. Langmuir plot (Eq.1) for Congo red adsorption on activated charcoal.

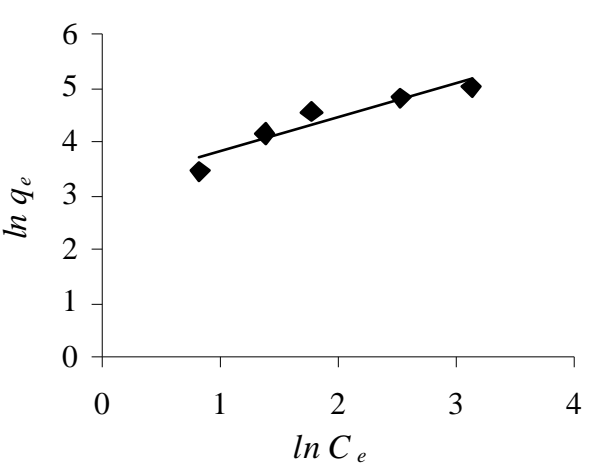

Fig. 6. Freundlich plot (Eq.2) for Congo red adsorption on activated charcoal.

Fig. 5 presents the Langmuir plot (Eq. 1) for the adsorption of Congo red onto activated charcoal. The straight-line form in the figure satisfactorily described the 
Langmuir model for equilibrium adsorption process. The values of the Langmuir parameters $K$ and $q_{\infty}$ ware respectively $0.0319 \mathrm{l} / \mathrm{g}$ and $500 \mathrm{mg} / \mathrm{g}$. These values indicated that the adsorption of Congo red on activated carbon were quite fast with high adsorption capacity. Fig. 6 presents Freundlich plot (Eq. 2) for the same adsorption system. As seen from the figure the Freundlich model also described the equilibrium adsorption process. The values of the Freundlich parameters $n$ and $K_{f}$ were 1.55 and 7.69 respectively. Obviously, under investigation both Freundlich and Langmuir model described the adsorption process.

\subsubsection{Adsorption kinetics}

The overall adsorption kinetics is usually presented by Lagergren equation (Eq. 3) [15]:

$$
\ln \left(q_{e}-q\right)=\ln q_{e}-k_{a d} t
$$

where $q$ and $q_{e}$ are respectively the amounts of dye adsorbed (mg/g) at time $t$ (min) and at equilibrium, and $k_{a d}$ is the rate constant for adsorption ( $\left.1 / \mathrm{min}\right)$.

The second-order kinetic model $[16,17]$ is also an effective model to describe the kinetics of an adsorption system and expressed as:

$$
t / q=1 / k q_{e}^{2}+t / q_{e}
$$

where $k$ (min $\mathrm{g} / \mathrm{mg}$ ) is the rate constant of second-order adsorption. If second-order kinetics is applicable, the plot of $t / q$ versus $t$ should show a linear relationship. There is no need to know any parameter beforehand and the equilibrium adsorption capacity, $q_{e}$ can be calculated from Eq. (4). Also, it is more likely to predict the behavior over the whole range of adsorption [16,17].

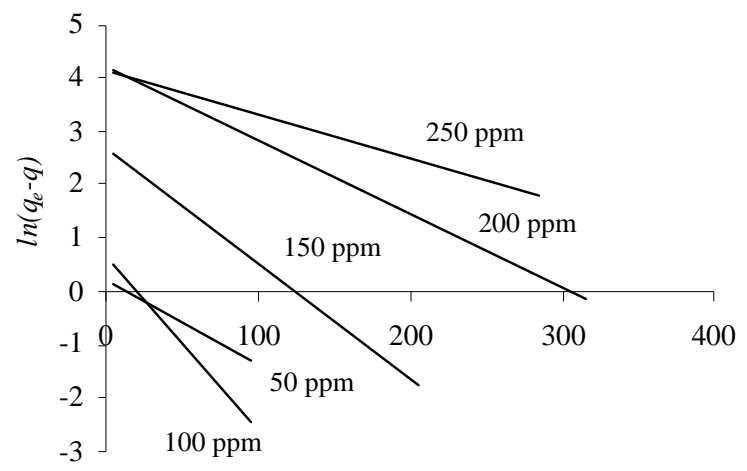

Time , $t$ (min)

Fig. 7. Lagergren adsorption kinetics represented by Eq. (3) for different initial dye concentrations.

The Lagergren kinetic data for various initial Congo red concentrations are presented in Fig. 7. From the figure it was revealed that the linearity regarding the Lagergren 
equation were very poorly described $\left(R^{2}=0.75-0.90\right)$. The fitted values of the rate constants $k_{a d}$ are presented in Table 1 and appeared deviation with initial dye concentration. As the adsorption rate constants were not followed any systematic deviation with concentration, it was not concluded that the Congo red - activated charcoal adsorption system followed the Legergren adsorption kinetics model.

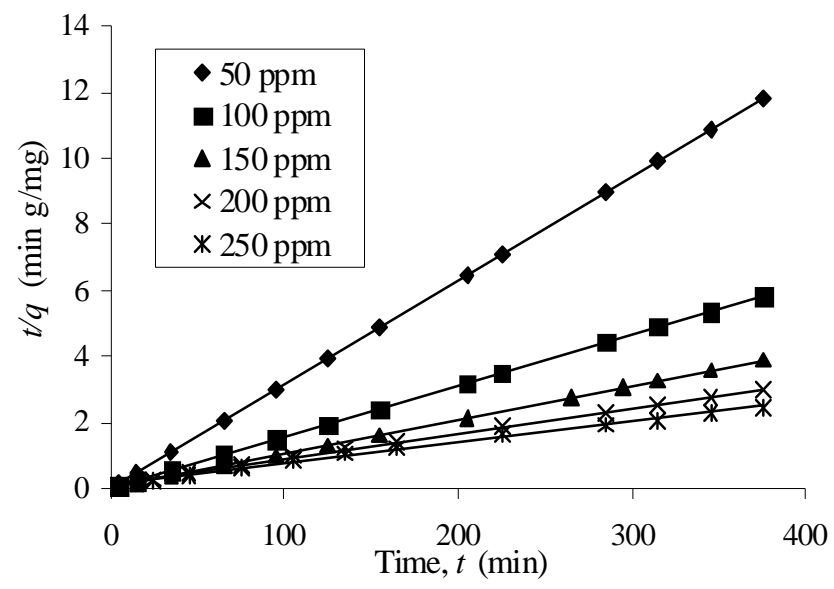

Fig. 8. Second-order adsorption kinetics represented by Eq. (4) for different initial Congo red concentrations.

The linear plots of $t / q$ versus $t$ shows a good agreement of experimental data with the second-order kinetic model for different initial dye concentrations is shown in Fig. 8. The second order rate constant, $k$ and $q_{e}$ were calculated from the intercept and slope of the plots of $t / q$ versus $t$ and are presented in Table 1 . The correlation coefficients $\left(R^{2}\right)$ for the second order kinetic model for all initial concentration were greater than 0.994 and also the calculated $q_{e}$ values were agreed very well with the experimental data. These indicate that the Congo red-activated charcoal adsorption system belongs to the second-order kinetic model.

Table 1. Adsorption rate constants for different initial concentration of Congo red.

\begin{tabular}{ccccc}
\hline & & \multicolumn{2}{c}{ Second-order kinetics } \\
\hline $\begin{array}{c}\text { Initial Congo-Red } \\
\text { Concentration } \\
(\mathrm{ppm})\end{array}$ & $\begin{array}{c}\text { Calculated } \\
q_{e}(\mathrm{mg} / \mathrm{g})\end{array}$ & $\begin{array}{c}\text { Lagergren kinetic } \\
k_{a d}(\mathrm{l} / \mathrm{min})\end{array}$ & $k(\mathrm{~min} \mathrm{~g} / \mathrm{mg})$ & $q_{e}(\mathrm{mg} / \mathrm{g})$ \\
\hline 50 & 31.82 & 0.016 & 0.051 & 32.26 \\
100 & 64.21 & 0.033 & 0.078 & 64.10 \\
150 & 96.06 & 0.022 & $5 \times 10^{-3}$ & 97.09 \\
200 & 125.1 & 0.014 & $5 \times 10^{-4}$ & 129.9 \\
250 & 151.5 & 0.008 & $3.5 \times 10^{-4}$ & 156.2 \\
\hline
\end{tabular}




\subsubsection{Effect of adsorbent dosage on removal}

The Removal $R$ is defined as follows:

$$
R=1-C_{e} / C_{0}
$$

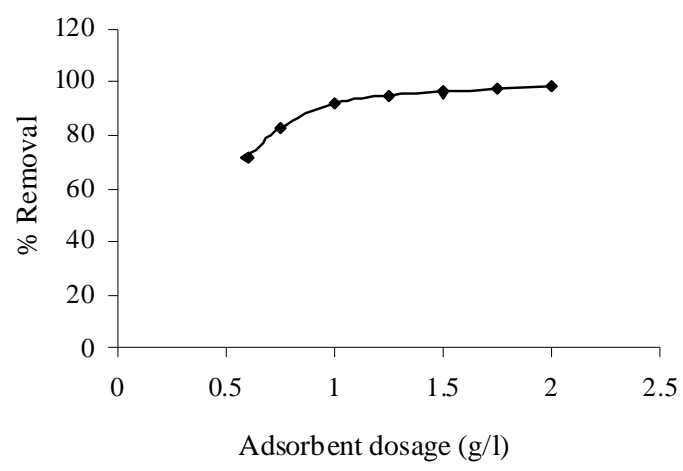

Fig. 9. Effect of adsorbent dosage on removal.

Fig. 9 shows the removal $R$ versus adsorption dosage $w_{a}$ for initial Congo red concentration of $100 \mathrm{ppm}$ at neutral $\mathrm{pH}$. As seen from the figure the removal $R$ increased with an increase of adsorbent dosage for the given initial concentration. Adsorbent had active sites to adsorb dye. If we increased adsorbent dosages, there were more active sites that could adsorb more dye to reach equilibrium. Empirically, the relation between percentage removal $(\% R)$ and adsorption dosage $\left(w_{\mathrm{a}}\right)$ is presented by the following relation:

$$
\% R=\frac{w_{a}}{0.0031+0.0083 w_{a}}
$$

\section{Conclusion}

In conclusion

a. Congo red could be removed up to $99 \%$ only by heating at $\mathrm{pH}<4$.

b. Lime wash was an effective method for the remove of Congo-Red and the removal process would be faster, as well as the settling velocity would be increased by using small amount of alum with it.

c. The adsorption of Congo red onto the activated charcoal could successfully be described by both the Langmuir and Freundlich isotherm.

d. The overall Congo red - activated charcoal adsorption kinetic was satisfactorily described by the second order kinetics model.

e. The activated charcoal could be used as an adsorbent for the effectively removal of Congo red from wastewater that disposed from textile industries. 


\section{References}

1. E. Clonfero, P. Venier, M. Granella, A. G. Levis, Med Lav. 81 (3), 222 (1990).

2. A. L. Ahmad, S. W. Puasa and M. M. D. Zulkali, Desalination 191 (1-3), 153 (2006). doi:10.1016/j.desal.2005.07.022

3. M. Neamtu, A. Yediler, I. Siminiceanu, M. Macoveanu, A. Kellrup, Dyes and Pigments 60 (1), 61 (2004). doi:10.1016/S0143-7208(03)00129-3

4. U. Bali, Dyes and Pigments 60, 187 (2004). doi:10.1016/S0143-7208(03)00145-1

5. F. Zhang, A. Yediler, X. Liang, and A. Kettrup, Dyes and Pigments 60, 1 (2004). doi:10.1016/S0143-7208(03)00111-6

6. S. Chakraborty, M. K. Purkait, S. D. Gupta, S. De, and J. K. Basu, Sep. Purif. Technol. 31, 141 (2003). doi:10.1007/s11157-005-1246-z

7. C. Namasivayam, and D. Kavitha, Dyes and Pigments 54, 47 (2002). doi:10.1016/S0143-7208(02)00025-6

8. I. Arvanitoyannis, I. Eleftheriadis, and E. Tsatsaroni, Chemosphere 18, 1707 (1989). doi:10.1016/0045-6535(89)90454-2

9. N. Kannan, and M. M. Sundaram, Dyes and Pigments 51, 25 (2001). doi:10.1016/S0143-7208(01)00056-0

10. B. Jae-Hyun, S. Dong-Ik, and J. Young-Woong, Sep Sci Technol. 35(3), 353 (2000). doi:10.1081/SS-100100161

11. M. Riera-Torres, C. Gutiérrez-Bouzán and M. Crespi, Desalination 252 (1-3), 53 (2010). doi:10.1016/j.desal.2009.11.002

12. A.R. Khataee, G. Dehghan, A. Ebadi, M. Zarei and M. Pourhassan, Bioresource Technology 101 (7), 2252 (2010). doi:10.1016/j.biortech.2009.11.079

13. S. Seshadri, P. L. Bishop, and A. M. Agha. Waste Management 14(2), 127 (1994). doi:10.1016/0956-053X(94)90005-1

14. F. Yuzhu, T. Viraraghavan, Advances in Environmental Research 7, 239 (2002). doi:10.1016/S1093-0191(01)00123-X

15. C. Namasivayam, and K. Ranganathan, Waste Management 14 (8), 709 (1994). doi:10.1016/0956-053X(94)90058-2

16. Y. S. Ho, and G. McKay, Water Res, 33 (2), 578 (1999). doi:10.1016/S0043-1354(98)00207-3

17. Y. S. Ho, and G. McKay, Process Biochem. 34 (5), 451 (1999). doi:10.1016/S0032-9592(98)00112-5 